\title{
A JUDICIALIZAÇÃO DE POLÍTICAS PÚBLICAS RELACIONADAS AOS MEDICAMENTOS DE ALTO CUSTO'
}

Adriane Bandeira Rodrigues

Liliane Satiro Borges

\section{INTRODUÇÃO}

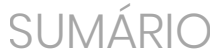

A Constituição da República Federativa do Brasil de 1988 (CRFB/1988) prevê a saúde como um direito social fundamental e impõe em seu artigo 196 que seja assegurado esse direito pelo Estado por meio de políticas públicas, garantindo a todos acesso igualitário e universal.

As políticas públicas no âmbito da saúde devem ser tratadas de forma abrangente, levando em consideração as necessidades da população, cujas ações devem estar voltadas à promoção, prevenção e recuperação da saúde.

Sob este prisma o Sistema Único de Saúde (SUS) foi implementado por meio da Lei n. 8.080, de 19 de setembro de 1990, denominada "Lei Orgânica da Saúde" tendo como objetivo administrar os serviços e as ações na área da saúde, inclusive a assistência farmacêutica conforme artigo 60, inciso l, alínea "d" (BRASIL, 1990).

Este trabalho tem como objetivo o estudo da "Judicialização de políticas públicas relacionadas a medicamentos de alto custo". Verificará os critérios definidos pelo Supremo Tribunal Federal (STF) para a imposição do fornecimento dos fármacos pelo Estado, o que ocorreu no julgamento da STA n. 175. Em seguida será analisada a decisão proferida no Incidente de Resolução de Demandas Repetitivas n. 030235511.2014.8.24.0054/50000 pelo Tribunal de Justiça de Santa Catarina e os

\footnotetext{
${ }^{1}$ Artigo extraído do Trabalho de Conclusão de Curso intitulado "A insuficiência de políticas públicas referentes a medicamentos de alto custo, frente ao processo de judicialização: Uma análise com relação à dimensão de saúde coletiva", da acadêmica Liliane Satiro Borges, orientado pela Prof. Ma. Adriane Bandeira Rodrigues e apresentado na Universidade do Extremo Sul Catarinense (UNESC), Curso de Direito, em julho de 2018.
} 
critérios determinados no respectivo julgado. Por fim, será instrumento de análise o Recurso Especial n. 1.657.156, com o seguinte tema objeto de afetação: "obrigatoriedade do poder público de fornecer medicamentos não incorporados em atos normativos do SUS".

\section{JUDICIALIZAÇÃO DAS POLITICAS PÚBLICAS}

Inicialmente, cumpre observar o sentido do termo judicialização. Conforme Barroso (2012) algumas indagações de ampla repercussão política e social, ao invés de serem decididas pelos poderes convencionais: o Congresso Nacional e o Poder Executivo, estão sendo decididas pelo Poder Judiciário.

Atualmente aglomeram-se pedidos judiciais requerendo a contribuição por parte do Estado para assegurar o direito à saúde, inclusas nessas ações inúmeras solicitações de medicamentos, que na sua maioria não são providos pelo SUS (CHIEFFI, BARATA, 2010).

Assim sendo, segundo Barroso (2012), um dos motivos centrais para a judicialização no País, originou-se do processo de redemocratização do Estado, que teve como ápice a promulgação da Constituição da República Federativa do Brasil de 1988. Nos últimos anos o Judiciário tornou-se um legítimo poder político, atribuindo eficácia às leis e à Constituição Federal.

De acordo com Rodrigues (2016), nesse aspecto, questiona-se a legitimidade da atuação do Poder Judiciário no que tange às decisões voltadas às políticas públicas, visto que os magistrados não foram escolhidos pelo povo a partir do processo democrático, nos termos da CRFB/1988. Entretanto, face aos vícios de representação no País, tornase legítimo o controle judicial, conforme os ditames do próprio texto constitucional, que assegura a inafastabilidade do controle jurisdicional, princípio esse previsto no artigo 5o inciso XXXV, nos seguintes termos: "A lei não excluirá da apreciação do Poder Judiciário lesão ou ameaça a direito." (BRASIL, 1990). 
A respeito, leciona Grau (2004, p. 335):

O Poder Judiciário é o aplicador último do direito. Isso significa que, se a Administração Pública ou um particular ou mesmo o Legislativo - de quem se reclama a correta aplicação do direito, nega-se a fazê-lo, o Poder Judiciário poderá ser acionado para o fim de aplicá-lo.

Assim, hodiernamente, o objeto de debate deixa de ser a legitimidade do controle judicial na seara das políticas públicas para tratar dos limites e conteúdo das decisões judiciais (BUCCI, 2013). Nesse tocante o STF se pronunciou na ADPF n. 45, da relatoria do Ministro Celso de Mello, entendendo que nos casos de abuso ou omissão estatal é legitima a atuação do Poder Judiciário (STF, 2004).

Dessa forma, as decisões judiciais proferidas nos processos onde são postulados medicamentos de alto custo deverão ser criteriosas, diante da demanda crescente capaz de gerar riscos ao gerenciamento das ações e serviços públicos de saúde, pondo em risco a dimensão coletiva da saúde (CHIEFFI; BARATA, 2010).

Conforme entendimento de Barroso (2009), tal fato decorre do crescente volume de ordens judiciais determinando que o Estado custeie tratamentos de elevado valor, cuja necessidade e eficácia em muitos casos são questionadas, sobretudo porque em muitas hipóteses tratamse de medicamentos em fase experimental (sem comprovação científica de eficácia) ou se tratam de tratamentos alternativos. Tal demanda gera impactos financeiros ao Estado, diante da necessidade de pessoal e despesas processuais. Aliado a isso provoca o incremento do volume de processos em trâmite perante o Poder Judiciário.

Nesse sentido, esclarece Barroso (2009, p. 35):

Tais excessos e inconsistências não são apenas problemáticos em si. Eles põem em risco a própria continuidade das políticas de saúde pública, desorganizando a atividade administrativa e impedindo a alocação racional dos escassos recursos públicos. No limite, o casuísmo da jurisprudência brasileira pode 
impedir que políticas coletivas, dirigidas à promoção da saúde pública, sejam devidamente implementadas. Trata-se de hipótese típica em que o excesso de judicialização das decisões políticas pode levar a não realização prática da Constituição Federal.

Os medicamentos pleiteados, em diversas hipóteses, são fármacos inovadores, e de alto custo, levando-se em consideração outras terapias indicadas para o tratamento da patologia, e, ainda, podem não estar disponíveis no mercado nacional. Não obstante, são objetos de prescrição como única alternativa de tratamento para a doença. Referida conduta dos médicos pode estar relacionada, em alguns casos, à influência promovida pelo poderio financeiro da indústria farmacêutica que realiza elevados investimentos na área do marketing perante os profissionais da área da saúde com fulcro a obtenção de lucratividade, sobretudo para viabilizar o retorno financeiro dos grandes investimentos exigidos para a inovação tecnológica (CHIEFFI; BARATA, 2010).

Segundo o CONASS:

Da mesma maneira como em outras áreas da saúde, também, nas questões relacionadas aos medicamentos, é importante que se tenha presente os vários interesses das indústrias, que precisam fazer investimentos cada vez maiores para obter um novo produto que se caracterize como um efetivo avanço terapêutico. Muitos dos lançamentos no mercado são de medicamentos com pequenas alterações ou adições nas moléculas já disponíveis. Essa é uma das estratégias utilizadas pelas empresas farmacêuticas para a obtenção de uma nova patente para determinado produto, o que assegura sua exclusividade na fabricação e comercialização. Por meio de estratégias de marketing, tais medicamentos são apresentados à classe médica e, até mesmo, a grupos específicos de usuários, como inovadores, ressaltandose de forma desproporcional suas vantagens em relação à terapêutica instituída ou a produto já ofertado pelo SUS. Frequentemente, apresentam preços elevados, com custo/tratamento significativamente superiores ao seu antecessor e desproporcionais em relação à resposta obtida no tratamento. (BRASIL, 2003). 
No campo das políticas públicas o que gera preocupação é a grande margem de discricionariedade que os juízes dispõem ao proferirem as decisões. Percebe-se que com o objetivo de promover a justiça social são concretizados direitos individuais, sem, "[...] contudo realizar uma análise do caso concreto contextualizada à realidade social, econômica e política do País, o que pode gerar graves prejuízos à própria continuidade da política pública e à saúde do ponto de vista coletivo." (RODRIGUES, 2016).

Nesse tocante, os estudiosos discutem os limites do direito de os cidadãos demandarem o Estado com vistas à obtenção de prestações positivas que atendam os seus direitos sociais fundamentais, os quais podem pertencer a duas categorias: direitos originários e direitos derivados a prestações (RODRIGUES, 2016).

Segundo Canotilho (2003), são direitos originários aqueles que decorrem de normas que impõem ao Estado um dever e, de outro lado, asseguram ao cidadão o direito de exigir prestações positivas.

De outro lado, ainda conforme ensina Canotilho (2003), os direitos derivados a prestações são aqueles em que se atribui legitimidade ao cidadão de exigir prestações do Estado que não estejam contempladas em política pública ou lei, mas que decorrem de dever do Estado,

Pertencem ao campo das prestações derivadas das ações judiciais referentes aos medicamentos que, embora não previstos na Relação Nacional de Medicamentos Essenciais (RENAME), dispensados à população, são objeto de pedidos perante o Poder Judiciário, sob o fundamento de que devem estar inseridos no dever do Estado de garantir a todos o direito social fundamental à saúde.

Portanto, mister o estabelecimento de critérios a serem observados pelas decisões judiciais, sob pena de os pedidos referentes aos medicamentos de alto custo serem deferidos em demandas individuais, causando prejuízo à coletividade, que continua dependente das políticas públicas. Nesse desiderato, foram estabelecidos alguns critérios a serem observados pelos magistrados, conforme será demonstrado. 


\section{PARÂMETROS FIXADOS PELO SUPREMO TRIBUNAL FEDERAL PARA O DEFERIMENTO DOS PLEITOS}

O julgado do STF na STA n. 175, de 17 de março de 2010, é paradigmático no que tange ao tema, visto que apontou os critérios que deveriam ser observados para o proferimento das decisões judiciais nos pedidos referentes a medicamentos e foram estabelecidos os seguintes parâmetros.

O primeiro critério refere-se à necessidade de exame da existência ou não de política pública referente à prestação almejada: $\mathrm{Na}$ hipótese de haver política pública do SUS contemplando a prestação, é reconhecido o direito subjetivo público do requerente; caso contrário, não havendo previsão da prestação na política pública, há três hipóteses a serem averiguadas: I - omissão legislativa ou administrativa; II - decisão administrativa no sentido de não dispensar o medicamento; e III - existência de proibição legal de dispensa. Nesse último caso, dispõe o artigo 12 da Lei Federal n. 6.360/1976 que "[...] nenhum dos produtos de que trata esta Lei, inclusive os importados, poderá ser industrializado, exposto à venda ou entregue ao consumo antes de registrado no Ministério da Saúde." (BRASIL, 1976). Assim sendo, o medicamento não poderá ser consumido sem o registro na Agência Nacional de Vigilância Sanitária (Anvisa), que atua na proteção da saúde da população por intermédio da fiscalização sanitária sobre a produção e a comercialização de produtos e serviços que se sujeitam à vigilância sanitária (STF, 2010 apud RODRIGUES, 2016, p. $147 / 148)$.

O segundo critério trata da motivação para a negativa de fornecimento do fármaco pelo sistema público de saúde. Nesse tocante, o Ministro Relator Gilmar Mendes apresenta duas hipóteses: 1) o SUS fornece terapia alternativa, mas não adequada a determinado paciente e 2) o SUS não dispõe de tratamento específico para determinada patologia. Na primeira situação é entendido que o Poder Judiciário pode deferir o pedido apesar de o fármaco não estar contemplado na política pública, caso demonstrada a ineficácia da alternativa terapêutica para o requerente, mas trata-se de medida de exceção, visto que deve ser 
prestigiado o uso dos fármacos disponíveis na rede pública, com custo menor para o Estado; já na segunda hipótese, não havendo tratamento alternativo para a patologia na rede pública, os pedidos judiciais podem ser concedidos, desde que não versem sobre medicamentos experimentais (STF, 2010).

O terceiro critério impõe a devida produção de provas no processo, considerando que os casos concretos não são idênticos. Assim, as circunstâncias fáticas demandam minucioso exame a fim de que as decisões possam conciliar as duas esferas do direito à saúde, quais sejam: a objetiva e a subjetiva. Segundo o Relator, a exigência da instrução probatória tem por objetivo evitar a "[...] produção padronizada de iniciais, contestações e sentenças, peças processuais que, muitas vezes, não contemplam as especificidades do caso concreto examinado." (STF, 2010).

No que tange aos parâmetros estabelecidos pela decisão paradigmática, Rodrigues (2016, p.150) entende que a “[...] decisão proferida pelo plenário do órgão de cúpula do Poder Judiciário, que ratificou os parâmetros fixados pela decisão monocrática da presidência do tribunal, os quais sevem de sugestão para as decisões referentes às demandas que envolvam direito à saúde".

Destarte, para que sejam atendidos os propósitos deste trabalho se analisará a decisão proferida no Incidente de Resolução de Demandas Repetitivas n. 0302355-11.2014.8.24.0054/50000 pelo Tribunal de Justiça de Santa Catarina, destacando-se os critérios estipulados pelo julgado. Importa destacar-se a relevância da análise da aludida decisão neste trabalho, visto que tal tese deve ser observada pelos juízes e demais órgãos do Tribunal de Justiça de Santa Catarina, pois tal incidente tem por propósito a uniformização da jurisprudência, nesse caso no âmbito do estado de Santa Catarina. 


\section{A TESE FIXADA NO INCIDENTE DE RESOLUÇÃO DE DEMANDAS REPETITIVAS N. 0302355- 11.2014.8.24.0054/50000 PELO TRIBUNAL DE JUSTIÇA DE SANTA CATARINA}

Tramitou perante a Vara da Fazenda Pública, Acidentes do Trabalho e Registros Públicos da Comarca de Rio do Sul determinada ação onde um cidadão ingressou em face do Município de Agronômica e do estado de Santa Catarina pleiteando o fornecimento dos fármacos: Vildagliptina + Metformina (GalvusMet), Levotiroxina, Ezetimiba + Sinvastatina e Carvedilol, por ser portador de Diabetes Melito Tipo II (CID10: E11 e E10.5), hipertensão, dislipidemia e hipotireoidismo (TJSC, 2016).

Restou concedida a tutela provisória para determinar a concessão dos medicamentos postulados. Citado, o município apresentou contestação arguindo preliminarmente sua ilegitimidade passiva, e no mérito, alegou a falta de recursos públicos para o custeio de medicamentos excepcionais e, por fim, requereu a produção de prova pericial e testemunhal (TJSC, 2016).

Ainda, o ente estatal, defendeu, preliminarmente, a ausência de interesse de agir quanto aos medicamentos Carvedilol, Levotiroxina e Glicazida porquanto fornecidos pelo Programa de Assistência Farmacêutica na Atenção Básica, sustentou, no mérito, a impossibilidade de fornecimento de medicação distinta da padronizada nos programas oficiais, uma vez que se encontra disponibilizada pelo SUS alternativa terapêutica compatível com a medicação solicitada. Argumentou, ainda, que a receita médica foi fornecida por profissional particular, o que não encontra abrigo na Recomendação da COMESC n. 01 de 30.07.2012, expôs sobre a essencialidade da realização de perícia e sobre a falta de provas quanto à hipossuficiência do postulante bem como sobre a necessidade da fixação de contracautela (TJSC, 2016).

Depois da realização de exame pericial, o Magistrado julgou procedente o pedido, ratificando a decisão que deferiu a tutela provisória, e condenou os réus a o fornecimento dos insumos, sob pena de "[...] multa 
mensal no valor equivalente a dois meses de uso dos medicamentos, a serem adquiridos nas farmácias da região, valor este que será sequestrado dos cofres [...], mediante comprovação dos gastos." (TJSC, 2016).

O estado apelou, apontando a ausência de interesse de agir quanto aos medicamentos padronizados, alegando que o requerente possui condições de arcar com os custos do tratamento; já o município apelou, alegando não possuir recursos econômicos para atender à condenação solidária, destacando a escassez de suas receitas (TJSC, 2016).

Depois da apresentação das contrarrazões, os autos ascenderam ao Tribunal de Justiça de Santa Catarina.

Distribuído o recurso ao relator, este entendeu de requerer de ofício, a instauração do Incidente de Resolução de Demandas Repetitivas (IRDR), sob a perspectiva constitucional da isonomia e da segurança jurídica, e por essa razão retirou o processo da pauta, uma vez que o mesmo entendeu por bem ampliar o debate sobre a questão, visto que havia quase 25 mil ações na área da saúde em trâmite no estado de Santa Catarina tratando da mesma questão de direito, tudo visando a obter a uniformização do entendimento da Corte diante da divergência acerca do tema. Com esse intuito, decidiu por afetar o julgamento ao Grupo de Câmaras de Direito Público (TJSC, 2016).

Destaca-se que os requisitos legais para a instauração do IRDR estavam presentes no caso em tela, conforme o artigo 976 do Código de Processo Civil:

É cabível a instauração do incidente de resolução de demandas repetitivas quando houver, simultaneamente: I - efetiva repetição de processos que contenham controvérsia sobre a mesma questão unicamente de direito;

II - risco de ofensa à isonomia e à segurança jurídica. (BRASIL, 2015).

O processamento do IRDR foi admitido pelo Grupo de Câmaras de Direito Público, na sessão de julgamento do dia 11 de maio de 2016, e em cumprimento ao disposto nos artigos 979, 982 e 983 do Código de 
Processo Civil, foram suspensos todos os processos pendentes (coletivos e individuais) que versavam sobre a temática. Na sequência, foi intimado o Ministério Público, assim como as partes, para a realização das respectivas manifestações (TJSC, 2016).

Foi determinado pelo relator que se oficiasse com cópia do despacho e do acórdão da instauração do IRDR, para que querendo se manifestassem acerca do oficio, as entidades a seguir relacionadas:

Secretaria de Estado da Saúde de Santa Catarina; Assembleia Legislativa do Estado de Santa Catarina; Tribunal de Contas do Estado de Santa Catarina; Ordem dos Advogados do Brasil, Seccional de Santa Catarina (OAB/SC); Defensoria Pública do Estado de Santa Catarina; Programa de Proteção e Defesa do Consumidor (PROCON/SC); Federação Catarinense de Municípios (FECAM); Associação Catarinense de Medicina (ACM); Associação Brasileira de Saúde Coletiva - Abrasco; Associação de Defesa dos Usuários de Seguro, Planos e Sistema de Saúde (Aduseps); Rede Humaniza SUS - RHS; Associação dos Usuários do Sistema Único de Saúde (ASSUS). (TJSC, 2016).

Depois das manifestações, de algumas entidades, os autos foram encaminhados à Procuradoria Geral de Justiça, cujo parecer da lavra da Exma. Dra. Gladys Afonso, aponta no sentido de que qualquer tratamento disponível na rede pública (prestações originárias) deve estar acessível a todos independentemente da situação financeira. Entretanto, para as terapias e insumos não protocolares (prestações derivadas) deve-se exigir o preenchimento do requisito hipossuficiência financeira, dentre outros critérios. Ao final propõe que o cidadão esgote primeiramente a esfera administrativa antes de recorrer ao Poder Judiciário (TJSC, 2016).

Com o intuito de facilitar a compreensão, no julgamento do IRDR foi realizada uma subdivisão do entendimento, levando em conta o fato de as prestações caracterizarem-se como originárias ou derivadas:

1. Demandas referentes a prestações originárias: tendo em vista que diante da hipótese em que o direito fundamental à saúde encontra-se regulado, ou seja, havendo uma política 
pública posta em prática, como no que diz respeito às terapias e medicamentos incluídos nas listas e protocolos oficiais do SUS, a função do Poder Judiciário, nesse caso, é garantir a sua efetividade, situação essa que se trata de direito subjetivo individual, em que o cidadão tem o poder de exigir do Estado (TJSC, 2016).

Nessa hipótese, em que a demanda é voltada ao recebimento de insumo ou terapia protocolar, é suficiente o receituário médico indicando a patologia e a necessidade de seu uso ou implementação do tratamento, cujo profissional pode ser ou não dos quadros públicos, aliada à demonstração de impossibilidade de obtenção na via administrativa (TJSC, 2016).

Diante da situação apresentada, restaram eleitos dois requisitos para a concessão judicial de remédio ou tratamento constante do rol do SUS: "1) a necessidade do fármaco perseguido e adequação à enfermidade apresentada, atestada por médico; e, concomitantemente, 2) a demonstração de impossibilidade de obtenção na via administrativa." (TJSC, 2016).

Nesse caso, resta claro que quando o objeto da demanda for o fornecimento de fármaco padronizado não há necessidade de comprovação da hipossuficiência financeira, sendo suficiente preencher os dois requisitos citados.

2. Demandas referentes a prestações derivadas: nessa hipótese, como se objetiva o fornecimento de fármaco ou tratamento ainda não abrangido por política pública, alguns requisitos devem anteceder ao reconhecimento do direito subjetivo do indivíduo e, em contrapartida, a obrigação do Estado em fornecê-lo. Diante desse contexto, lista-se como requisito essencial a comprovação da "hipossuficiência financeira do doente e de seu núcleo familiar", de modo que seja impossível arcar com custeio da terapia necessária (TJSC, 2016).

Nesse caso, para comprovar a carência financeira não basta a simples declaração do paciente, uma vez que não se trata de hipótesesimilar a que permite a gratuidade judiciária, onde o Estado deixa de arrecadar 
recurso, mas, "[...] ao contrário, está-se diante de reconhecimento de obrigação positiva por parte do Estado, ensejando despesa imprevista a incidir em um orçamento já escasso para a implementação das políticas públicas existentes." (TJSC, 2016).

No caso em comento, não basta a simples declaração do enfermo, é necessário produzir provas claras dessa alegação, sendo indispensável a comprovação da hipossuficiência inclusive do núcleo familiar.

Assim, nessa perspectiva compete ao autor demonstrar a alegada carência financeira, pois tal requisito se traduz em fato constitutivo do direito subjetivo. Caso haja dúvidas com relação à hipossuficiência do autor e de seu núcleo familiar, nesse caso deve ser determinada a realização de estudo social tendo em vista que essa é a ferramenta capaz de apontar as peculiaridades de cada caso concreto, o que auxiliará o julgador na elucidação da capacidade financeira do demandante. Entretanto o próprio interessado pode reunir provas que sejam capazes de indicar de plano sua impossibilidade de arcar com os custos do tratamento pretendido, deixando o estudo social somente para as hipóteses mais nebulosas (TJSC, 2016).

Conforme posicionamento firmado no IRDR (TJSC, 2016) "[...] assenta-se a comprovação da hipossuficiência financeira como requisito imprescindível ao nascimento da obrigação estatal de custear fármaco não padronizado pela rede pública".

Juntamente com o requisito da demonstração da hipossuficiência soma-se a demonstração da necessidade do medicamento reclamado, aliada à inexistência na listagem oficial do SUS de fármaco de atuação idêntica ou similar, que possa tratar a doença referida. E, caso o paciente já tenha utilizado o medicamento fornecido pelo SUS, a comprovação de sua ineficácia. Nesse caso, faz-se necessária a realização de perícia médica com o objetivo de subsidiar a decisão judicial na matéria (TJSC, 2016).

Porém, deve-se diferenciar a pretensão voltada à garantia do mínimo existencial, daquela referente ao máximo desejável. Nesse sentido, o Tribunal de Justiça de Santa Catarina se manifestou: 
Quando o remédio ou procedimento postulado referese à enfermidade para a qual inexiste política pública, permitindo-se aferir que tal omissão atinge a dignidade da pessoa humana, na medida em que condiz com os ditames básicos de cuidados à saúde, estar-se-á diante de pretensão condizente com a noção de mínimo existencial. Ao contrário, quando houver política pública disponibilizando droga diversa da perseguida judicialmente, ou a ausência de política se der em razão de se tratar de fármaco experimental ou de custo exorbitante, há que se aprofundar a análise. Isso porque a decisão judicial estará influindo diretamente na seara da Administração, de modo a, obrigatoriamente, ter-se que ponderar as consequências práticas do comando emanado pela autoridade judiciária, devendo-se, pois, sopesar a pretensão com o princípio da reserva do possível. (TJSC, 2016).

Portanto, quando se tratar de medicamentos não listados pelo sistema público de saúde, além da necessidade de comprovação da hipossuficiência financeira do postulante e do grupo familiar, haverá também a necessidade de se comprovar a inexistência ou ineficácia da política pública referente à doença, devendo-se analisar se a pretensão almeja o mínimo existencial ou o máximo prometido, neste último caso, sujeitando-se ao exame relativo à reserva do possível.

Entretanto, com relação aos medicamentos constantes na RENAME, não há necessidade de comprovação de hipossuficiência financeira, porém, deverá ser comprovada a necessidade do medicamento solicitado e adequação à enfermidade apresentada, atestada por médico, e simultaneamente a demonstração de impossibilidade de obtenção na via administrativa (TJSC, 2016).

Diante do exposto foram firmadas as seguintes teses jurídicas:

Para a concessão judicial de remédio ou tratamento constante do rol do SUS, devem ser conjugados os seguintes requisitos: (1) a necessidade do fármaco perseguido e adequação à enfermidade apresentada, atestada por médico e, concomitantemente; (2) a demonstração, por qualquer modo, de impossibilidade 
ou empecilho à obtenção na via administrativa (Tema 350 do STF).

Para a concessão judicial de fármaco ou procedimento não padronizado pelo SUS, são requisitos imprescindíveis: (1) a efetiva demonstração de hipossuficiência financeira; (2) ausência de política pública destinada à enfermidade em questão ou sua ineficiência, somada à prova da necessidade do fármaco buscado por todos os meios, inclusive mediante perícia médica; (3) nas demandas voltadas aos cuidados elementares à saúde e à vida, ligando-se à noção de dignidade humana (mínimo existencial), dispensamse outras digressões; (4) nas demandas claramente voltadas à concretização do máximo desejável, faz-se necessária a aplicação da metodologia da ponderação dos valores jusfundamentais, sopesando-se eventual colisão de princípios antagônicos (proporcionalidade em sentido estrito) e circunstâncias fáticas do caso concreto (necessidade e adequação), além da cláusula da reserva do possível. (TJSC, 2016, grifo do autor).

Assim sendo, depois do julgamento do IRDR, pelo Tribunal de Justiça de Santa Catarina, estabeleceram-se critérios a serem observados pelos magistrados frente às demandas referentes ao direito à saúde, a fim de uniformizarem-se as decisões proferidas, para que não haja mais discrepância sobre o tema, conforme artigo 985 do Código de Processo Civil:

Art. 985 Julgado o incidente, a tese jurídica será aplicada: I - a todos os processos individuais ou coletivos que versem sobre idêntica questão de direito e que tramitem na área de jurisdição do respectivo tribunal, inclusive àqueles que tramitem nos juizados especiais do respectivo Estado ou região;

II - aos casos futuros que versem idêntica questão de direito e que venham a tramitar no território de competência do tribunal, salvo revisão na forma do art. 986.

$\S 1$ 음 Não observada a tese adotada no incidente, caberá reclamação. 
§ 2o Se o incidente tiver por objeto questão relativa a prestação de serviço concedido, permitido ou autorizado, o resultado do julgamento será comunicado ao órgão, ao ente ou à agência reguladora competente para fiscalização da efetiva aplicação, por parte dos entes sujeitos à regulação, da tese adotada. (BRASIL, 2015).

Depois da análise do julgamento do IRDR se passará ao estudo do Recurso Especial n. 1.657.156, com o objetivo de verificar os critérios estabelecidos pelo Superior Tribunal de Justiça (STJ) sobre a matéria. É importante destacar que por se tratar de Recurso Especial Repetitivo, os tribunais e juízes em todo o território nacional deverão observar os parâmetros estabelecidos na referida decisão nas demandas relacionadas à matéria.

\section{O RECURSO ESPECIAL N. 1.657.156 E OS SEUS TRÂMITES}

O caso tratado no recurso refere-se a uma paciente, recorrida, portadora de glaucoma crônico bilateral (CID 440.1), que necessita fazer uso contínuo dos seguintes medicamentos: Colírios: Azorga $5 \mathrm{ml}$, Glaub $5 \mathrm{ml}$ e Optive $15 \mathrm{ml}$, conforme prescrição fornecida por médico em atendimento pelo SUS. A Corte de origem entendeu que foi devidamente demonstrada a necessidade da paciente em receber os fármacos pleiteados bem como sua hipossuficiência financeira para aquisição dos medicamentos. Entretanto, o estado do Rio de Janeiro, recorrente, alegou que a assistência farmacêutica do estado somente pode ser prestada por meio da entrega de medicamentos prescritos em acordo com os Protocolos Clínicos incorporados ao SUS ou, "[...] na hipótese de inexistência de protocolo, com o fornecimento de medicamentos constantes em listas editadas pelos entes públicos". Requereu ainda que seja reconhecida a possibilidade de substituição do fármaco demandado por outros já padronizados e disponibilizados (STJ, 2018). 
O presente recurso preencheu os pressupostos de admissibilidade, o que viabilizou a apreciação e julgamento da tese em recurso repetitivo.

É importante destacar que, o tema afetado, "obrigatoriedade do poder público de fornecer medicamentos não incorporados em atos normativos do SUS" se refere unicamente ao fornecimento de fármacos, previsto no inciso I do artigo 19-M da Lei n. 8080/1990 que consiste na dispensação de medicamentos de interesse para a saúde, sendo que a prescrição deve estar em consonância com as diretrizes terapêuticas dispostas em "protocolo clínico para a doença ou o agravo à saúde a ser tratado ou, na falta do protocolo, em conformidade com o disposto no artigo 19-P." (BRASIL, 1990).

A temática acerca do fornecimento de medicamentos possui ampla jurisprudência no Superior Tribunal de Justiça e no Supremo Tribunal Federal. Ambos os tribunais têm firmado entendimento nas ações que têm por objeto o fornecimento de medicamentos, no sentido de ser devido o provimento de fármacos não incorporados em atos normativos do SUS (STJ, 2018).

Diante desse contexto, restaram fixados os parâmetros na tese firmada no respectivo julgamento, sendo que o primeiro exige que seja demonstrado pela parte autora por meio de laudo médico circunstanciado e devidamente fundamentado, expedido por médico que assiste o paciente, que o medicamento receitado Ihe seja imprescindível. É necessário também comprovar a ineficiência dos medicamentos disponibilizados pelo SUS para o tratamento pretendido (STJ, 2018).

O Enunciado n. 15 da I Jornada de Direito da Saúde realizada pelo Conselho Nacional de Justiça (CNJ) dispõe que o laudo médico deve conter algumas informações essenciais:

O medicamento indicado, contendo a sua Denominação Comum Brasileira (DCB) ou, na sua falta, a Denominação Comum Internacional (DCl); o seu princípio ativo, seguido, quando pertinente, do nome de referência da substância; posologia; modo de administração; e período de tempo do tratamento; e, em caso de 
prescrição diversa daquela expressamente informada por seu fabricante, a justificativa técnica. (CNJ, 2014).

O segundo critério fundamenta-se na necessidade de comprovação da hipossuficiência daquele que pleiteia o medicamento. Vale destacar que não se exige a comprovação de miserabilidade ou pobreza, mas a demonstração de que o requerente não possui condições financeiras de arcar com os custos referentes à aquisição do fármaco prescrito (STJ, 2018).

O terceiro e último critério, é que o fármaco pretendido já tenha sido aprovado pela Anvisa (STJ, 2018), conforme imposição legal, do artigo 19-T, inciso II, da Lei n. 8.080/1990: “Art. 19-T. São vedados, em todas as esferas de gestão do SUS: [...] II - a dispensação, o pagamento, o ressarcimento ou o reembolso de medicamento e produto, nacional ou importado, sem registro na Anvisa." (BRASIL, 1990).

Cumpre destacar-se que o presente recurso foi julgado no dia 25 de abril de 2018 e publicada a decisão no dia 4 de maio de 2018, e diante do exposto foram firmadas as seguintes teses jurídicas:

Constitui obrigação do Poder Público o fornecimento de medicamentos não incorporados em atos normativos do SUS, desde que presentes, cumulativamente, os requisitos fixados neste julgado, a saber:

I- Comprovação, por meio de laudo médico fundamentado e circunstanciado expedido por médico que assiste o paciente, da imprescindibilidade ou necessidade do medicamento, assim como da ineficácia, para o tratamento da moléstia, dos fármacos fornecidos pelo SUS;

II - Incapacidade financeira de arcar com o custo do medicamento prescrito; e III - Existência de registro na ANVISA do medicamento. (STJ, 2018, grifo do autor).

Além da fixação dos referidos critérios, restou determinado que, depois do trânsito em julgado, os órgãos julgadores, comuniquem ao Ministério da Saúde e à Comissão Nacional de Tecnologias do SUS (Conitec) que procedam a estudos quanto à viabilidade de incorporação do medicamento no âmbito do SUS (STJ, 2018). 
É importante destacar que no caso concreto foi estabelecida a modulação dos efeitos desse julgamento, sendo que os tribunais e juízes deverão observá-lo para os processos que forem distribuídos a partir da sua conclusão (STJ, 2018).

Vale destacar que a decisão proferida no Recurso Especial também gera impactos nos processos que envolvem pedidos de medicamentos propostos em Santa Catarina, embora haja a decisão proferida no IRDR que também estabelece critérios para o deferimento dos pedidos, aplicável exclusivamente no território do estado.

Ocorre que o Superior Tribunal de Justiça se trata de tribunal de hierarquia superior com relação aos tribunais estaduais e tem o papel de uniformizar a interpretação da lei infraconstitucional em todo o território nacional.

\section{IMPACTOS DA JUDICIALIZAÇÃO SOBRE A DIMENSÃO DA SAÚDE COLETIVA}

Conforme demonstrado no decorrer do presente trabalho existe um número crescente de ações judiciais individuais que visam à obtenção de medicamentos, mas esse modelo de ação contempla a dimensão individual da saúde uma vez que a decisão judicial favorecerá somente o autor da demanda.

As ações individuais, via de regra, beneficiam quem tem mais conhecimento, mais acesso e informação, desse modo o atendimento de demandas individuais e a judicialização não favorece os menos esclarecidos, que ficam na sujeição da política pública, o que ofende o princípio da universalidade do SUS (CRF-SC, 2016).

Portanto, a tutela individual não está em conformidade com o tratamento dado à saúde pela Constituição da República Federativa do Brasil de 1988, pois, segundo Rodrigues (2016, p.203), após a Constituição restou [...] elevada à categoria de direito social fundamental do cidadão, caracterizando-se como um bem pertencente a toda sociedade brasileira, ou seja, é de titularidade de cada cidadão e de todos, coletivamente". 
As políticas públicas têm por objetivo a prestação coletiva pelo Estado, visto que destinadas a toda população, dessa maneira observa-se que a judicialização da saúde gera impactos sobre a dimensão coletiva da saúde, uma vez que as demandas individuais exigem altos custos para a administração pública além de dispêndios ao Poder Judiciário. Assim a verba pública que poderia ser utilizada para a ampliação de políticas públicas e consequentemente atender um maior número de cidadãos, contemplando a dimensão coletiva de saúde, é utilizada em demandas individuais.

Nesse contexto, vale destacar-se a importância da determinação do STJ de expedição de ofícios aos órgãos competentes após o trânsito em julgado das decisões que deferem pedidos de medicamentos. Tal medida servirá para que haja estudos sobre a viabilidade da implementação dos fármacos com o maior índice de pedidos judiciais na lista de medicamentos disponibilizados pelo SUS, o que poderá contribuir para o fortalecimento da saúde do ponto de vista coletivo.

\section{CONSIDERAÇÕES FINAIS}

Esse capítulo se propôs estudar a judicialização de políticas públicas relacionadas aos medicamentos de alto custo, visto que embora haja a RENAME, instrumento de orientação para a dispensação de fármacos, a mesma é considerada incompleta. Desse modo, as políticas públicas de medicamentos são insuficientes para atender às demandas existentes. Diante desse cenário tem-se o processo de judicialização da política, no qual a atuação do Poder Judiciário é tida como legítima principalmente frente ao princípio da inafastabilidade do controle jurisdicional, consagrado no artigo 5으, inciso XXXV, da Constituição da República Federativa do Brasil de1988.

Entretanto, há limites para a atuação do Poder Judiciário, uma vez que se tenta evitar interpretações desprovidas de critério que possam colocar em risco o orçamento público, acarretando prejuízos ao direito coletivo à saúde. 
A presente pesquisa destacou os critérios estabelecidos no julgamento do Agravo Regimental na STA n. 175 pelo Supremo Tribunal Federal em março de 2010. É importante observar que essa decisão constitui em um marco emblemático ao delimitar os requisitos a serem adotados nas ações em que são requeridas prestações e serviços na área da saúde, estabelecendo: a verificação quanto à existência ou não de política pública referente à prestação pretendida: caso o medicamento não seja fornecido, os motivos pelos quais não consta nas listas públicas e a necessária instrução probatória, tendo em vista que os casos não são iguais, devendo ser comprovada à necessidade e eficácia do tratamento pretendido.

Em seguida se passou à análise dos critérios estabelecidos na decisão proferida no IRDR n. 0302355-11.2014.8.24.0054/50000 pelo Tribunal de Justiça de Santa Catarina. Restou demonstrada a relevância da análise da tese fixada, tendo em vista que deverá haver uma uniformização da jurisprudência, sendo que os tribunais e juízes deverão observá-la nos julgamentos referentes à matéria, observando os seguintes critérios: em se tratando de fármaco ou tratamento constante do rol do SUS, deve-se comprovar a necessidade do medicamento pretendido além da demonstração da impossibilidade de obtenção pela via administrativa. Para a obtenção pela via judicial de fármaco ou procedimento não padronizado pelo SUS, faz-se necessária a comprovação da hipossuficiência financeira, a ausência de política pública referente à enfermidade, juntamente com prova da necessidade do medicamento.

Por último se analisou o Recurso Especial n. 1.657 .156 com o objetivo de verificar os critérios estabelecidos. Tal recurso foi analisado por representar um marco nas decisões referentes ao fornecimento de medicamentos, uma vez que se trata de Recurso Especial Repetitivo e a tese firmada nesse julgamento deverá ser observada pelos tribunais e juízes quando se tratar demandas relacionadas à matéria. Os critérios estabelecidos foram: há obrigação do Poder Público em fornecer o fármaco não incorporado no SUS, desde que atenda, ao mesmo tempo, a comprovação da imprescindibilidade ou necessidade do medicamento, assim como da ineficácia dos medicamentos fornecidos pelo SUS, a 
hipossuficiência financeira para arcar com o custo do tratamento e a existência de registro do fármaco na Anvisa.

Ainda resultante da decisão do Recurso Especial se destacou a determinação de que depois do trânsito em julgado, os órgãos julgadores, comuniquem ao Ministério da Saúde e à Comissão Nacional de Tecnologias do SUS que procedam a estudos quanto à viabilidade de incorporação do medicamento no âmbito do SUS.

Considera-se esse um grande avanço, visto que o objetivo dessa determinação é permitir a análise dos medicamentos com maior incidência de pedidos judiciais para verificação da possibilidade de implementação no rol de fármacos disponibilizados pelo SUS. Isso porque o aumento de ações individuais pleiteando medicamentos é reflexo da insuficiência de políticas públicas, uma vez que no cenário atual essas demandas favorecem exclusivamente ao autor da ação, contribuindo assim para a dimensão individual do direito à saúde em detrimento da coletividade.

Assim, a judicialização das políticas públicas relacionadas aos medicamentos de alto custo não é a melhor alternativa para a consolidação da dimensão coletiva da saúde, porém no futuro poderá contribuir para o seu fortalecimento na medida em que a política pública comece a contemplar os medicamentos objeto de reiterados pedidos judiciais em ações individuais.

\section{REFERÊNCIAS}

BARROSO, L. R. Da falta de efetividade à judicialização excessiva: direito à saúde, fornecimento gratuito de medicamentos e parâmetros para a atuação judicial. Revista Jurisprudência Mineira, Belo Horizonte, v. 188, n. 60, p. 29-60, jan./mar. 2009.

BARROSO, L. R. Judicialização, ativismo judicial e legitimidade democrática. Thesis, Rio de Janeiro, v. 5, p. 23-32, 2012.

BRASIL. Conselho Nacional de Secretários de Saúde. Para entender a gestão do SUS. Brasília, DF: CONASS, 2003. Disponível em: http://bvsms.saude.gov. br/bvs/publicacoes/para_entender_gestao.pdf. Acesso em: 7 jan. 2018. 
BRASIL. Constituição 1988. Constituição da República Federativa do Brasil de 1988. Brasília, DF, 1988. Disponível em: http://www.planalto.gov.br/ ccivil_03/constituicao/constituicao.htm. Acesso em: 2 fev. 2018.

BRASIL. Lei n. 13.105, de 16 de março de 2015. Código de Processo Civil. Brasília, DF, 2015. Disponível em:

http://www.planalto.gov.br/ccivil_03/_ato2015-2018/2015/lei/l13105.htm. Acesso em: 2 maio 2018.

BRASIL. Lei n. 6360, de 23 de setembro de 1976. Dispões sobre a vigilância sanitária a que ficam sujeitos os medicamentos, as drogas, os insumos terapêuticos e correlatos, cosméticos, saneantes e outros produtos e dá outras providências. Brasília, DF, 1976. Disponível em:

http://www.planalto.gov.br/CCIVIL_03/LEIS/L6360.htm. Acesso em: 3 jan. 2018.

BRASIL. Lei n. 8.080, de 19 de setembro de 1990. Dispõe sobre as condições para a promoção, proteção e recuperação da saúde, a organização e o funcionamento dos serviços correspondentes e dá outras providências. Brasília, DF, 1990. Disponível em: http://www.planalto.gov.br/ccivil_03/leis/L8080. htm. Acesso em: 28 jan. 2018.

BUCCI, M. P. D. Fundamentos para uma teoria jurídica das políticas públicas. São Paulo: Saraiva, 2013.

CANOTILHO, J. J. G. Direito Constitucional e teoria da Constituição. 7. ed. Coimbra: Almedina, 2003.

CHIEFFI, A. L.; BARATA, R. de C. B. Ações judiciais: estratégia da indústria farmacêutica para introdução de novos medicamentos. Revista Saúde Pública, São Paulo, v. 44, n. 3, p. 421-429, 2010.

CONSELHO NACIONAL DE JUSTIÇA (CNJ). Recomendação n. 15, de 14 e 15 de maio de 2014. São Paulo, 2014. Disponível em:

http://www.cnj.jus.br/programas-e-acoes/forum-da-saude/i-jornada-de-direito-da-saude. Acesso em: 12 abr. 2018.

GRAU, E. R. A ordem econômica na Constituição de 1988. 9. ed. São Paulo: Malheiros Editores, 2004. 
RODRIGUES, A. B. A Judicialização do fornecimento de medicamentos frente à universalidade do Sistema Único de Saúde. 2016. 322 f. Dissertação (Mestrado em Desenvolvimento Socioeconômico) - Programa de Pós-Graduação em Desenvolvimento Socioeconômico. Universidade do Extremo Sul Catarinense, Criciúma, 2016.

SUPERIOR TRIBUNAL DE JUSTIÇA (STJ). Recurso Especial n. 1.657.156. Relator: Ministro Benedito Gonçalves. Brasília, DF, 25 abr. 2018. Disponível em: http://www.stj.jus.br. Acesso em: 2 jun. 2018.

SUPREMO TRIBUNAL FEDERAL (STF). Arguição de descumprimento de preceito fundamental n. 45. Requerente: Partido da Social Democracia Brasileira (PSDB). Requerido: Presidente da República. Relator: Ministro Celso de Mello. Brasília, DF, 29 abr. 2004. Disponível em: http://www.stf.jus.br. Acesso em: 8 jan. 2018.

SUPREMO TRIBUNAL FEDERAL (STF). STA/175 - AG. REG. na Suspensão de Tutela Antecipada. Agravante: UNIÃO. Agravado: Ministério Público Federal e outros. Relator: Ministro Gilmar Mendes. Brasília, DF, 17 mar. 2010. Disponível em: http://www.stf.jus.br. Acesso em: 8 jan. 2018.

SUPREMO TRIBUNAL FEDERAL (STF). STA/175. Requerente: União. Requerido: Tribunal Regional Federal da 5a Região (Apelação Cível n. 408729-CE2006.81.00.003148-1). Relator: Ministro Gilmar Mendes. Brasília, DF, 18 set. 2009. Disponível em: http://www.stf.jus.br. Acesso em: 8 jan. 2018.

TRIBUNAL DE JUSTIÇA DE SANTA CATARINA (TJSC). IRDR n. 030235511.2014.8.24.0054/50000. Relator: Desembargador Rolnei Danieli. Florianópolis, 2016. Disponível em: http://www.tjsc.jus.br. Acesso em: 2 jun. 2018. 